\title{
Elena Vega-Sampayo, La poesía esencial de José Corredor-Matheos, León, Universi- dad de León, 2008, 572 pp.
}

Que José Corredor Matheos es uno de los poetas más destacados de su generación -además de crítico de arte, traductor o antólogo- es, quizás, tópico recordarlo a estas alturas, pero no por ello menos necesario. Como tampoco deja de serlo el añadir que, de entre esos mismos poetas ha sido uno de los que mejor ha sabido reinventarse, salir del encasillamiento al que antologías, críticos o, incluso, lectores, han tendido a relegarlos, a lo que ha contribuido - ¿para qué negarlo?- en buena medida la propia producción de muchos de ellos. Sin embargo, en el caso de Corredor Matheos, como en el de Ángel Crespo, Jesús Lizano, Enrique Badosa, Lorenzo Gomis o Gabino-Alejandro Carriedo, por citar algunos, encontramos una obra que ha sabido renovarse con el tiempo, o, mejor dicho, que ha conseguido permanecer viva, palpitante, adquiriendo esa condición de intemporalidad o universalidad tan poco frecuente en un autor contemporáneo y, mucho menos, en un autor vivo. A ello ha contribuido no sólo la lúcida elección de los temas abordados, que huyen de la rigidez a que obligaba aquella poesía del medio siglo vinculada a lo social y tan del gusto de su generación, sino también un uso de las formas, sean estas tradicionales o no, muy personal. Podríamos apuntar ya que una de las características definitorias y singulares de su quehacer poético será el hecho de que en su obra forma y contenido nazcan de una visión de la poesía marcada por el despojamiento y la levedad propios de las culturas orientales, de los místicos o de poetas que tuvieron como objetivo -y obsesión- un ideal de pureza en ocasiones inalcanzable, tal es el caso de Juan Ramón Jiménez, de Rainer Maria Rilke o del norteamericano William Carlos Williams.

El amplio estudio que aquí comentamos, realizado por Elena Vega-Sampayo, ayuda en buena medida a desbrozar el bosque corredoriano, a acercar al profano, a orientar al aficionado a su poesía y a profundizar, sobre todo en lo tocante a algunos aspectos insólitos de la misma, al estudioso y conocedor de su obra. Por ello, y sirva como ejemplo, uno de las intereses de este estudio consiste en abarcar la producción del poeta hasta el momento actual, lo que implica vislumbrar, junto a las tres etapas tradicionalmente señaladas por la crítica a la hora de clasificar su producción ("poesía de la vida cotidiana", hasta 1960; "poesía de la existencia", hasta 1971; y "poesía del despojamiento", a partir de Carta a Li-Po y hasta El don de la ignorancia, en 2004), la existencia, nos dirá la propia autora, de "una cuarta etapa a la que también parecen adscribirse poemas escritos con posterioridad a este título". También es destacable la pretensión de "apuntar cierto cruce de tendencias observable más allá del proceso de asimilación y aprovechamiento progresivos que se lleva a cabo en la trayectoria corredoriana de los cuatro libros publicados de 1975 a 2004 [Carta a Li-Po (1975), Y tu poema empieza (1987), Jardín de arena (1994) y El don de la ignorancia (2004)] y que traza 
una ineludible raya secuencial" que precisa los núcleos fundamentales de una obra, como la del manchego, densa y no siempre fácil, pese a su aparente levedad.

La organización del material que constituye este trabajo, fruto de una tesis doctoral dirigida por el profesor José María Balcells, es clara y precisa. Tras recorrer brevemente algunas de las claves de la biografía de Corredor-Matheos que puedan ser de utilidad para el estudio de su obra, la autora analiza su trayectoria poética y las etapas que la constituyen en lo que ella misma denomina un "estudio diacrónico de su creación poética". Sirve ello como pretexto para mostrar un primer acercamiento a las constantes de su lírica, a los puntos cardinales sobre los que se orienta el grueso de una producción no excesivamente extensa, pero no por ello menos compleja.

A continuación se estudia la teoría poética del autor, a la que casi debería denominarse teoría "artística", pues se analiza su visión de la poesía, pero también del arte en general a través de sus escritos, tanto los que conciernen a su propia obra, como sus textos críticos sobre otros poetas, en su mayoría coetáneos, sin olvidar -no podía ser de otro modo- algunos procedentes de su amplia labor como crítico de arte. A través del estudio de estos textos, podemos vislumbrar ya algunas de las constantes citadas en el sucinto análisis de sus libros y que nos irán preparando para el grueso de este estudio, sirviendo claramente de base para la materia de los capítulos siguientes, verdadero núcleo analítico.

Podría hablarse así, de tres conceptos fundamentales sobre los cuales, según la autora, se sustenta la producción del autor de Carta a Li-Po: la trascendencia, el silencio y la esencialidad. Para completar estas primeras conclusiones, se realiza también un breve recorrido por buena parte de los recursos más caros al poeta en esa constante búsqueda de lo esencial, así como por sus símbolos más habituales, las abundantes antítesis y paradojas que recorren sobre todo su producción más orientalista y su peculiar uso de algunos tropos como la metáfora. Una utilización que resulta original y novedosa, pues, a través de su desnudez, su poesía se desliga en cierta medida de la costumbre, arraigada en la tradición literaria occidental, que suele destacar tal vez en exceso su alta carga cognitiva y expresiva. La presencia de un constante simbolismo servirá al poeta también para rechazar "el intelectualismo, el voluntarismo y el utilitarismo como elementos definitorios de la poesía".

Las influencias extremo-orientales y otras, citadas más arriba, son diseccionadas en el capítulo siguiente, "Resonancias". Influencias que, como el budismo zen, el taoísmo o el sufismo y la obra del poeta medieval persa Omar Jayyam han permitido esa evolución y asimilación de culturas que hacen del despojamiento, al que CorredorMatheos aspira en su palabra poética, un caso único y singular en nuestra lírica, por su asimilación plena -que no imitación- de las culturas de Oriente. No hay una pretensión esteticista de crear una lírica "orientalizante", sino una búsqueda de respuestas, de conocimiento y profundización a través de la poesía, que encuentra su camino en la visión de mundo de las filosofías orientales. También se recorren, en el capítulo siguiente, aquellos aspectos de la métrica empleada por el poeta que resultan más relevantes, desde el versolibrismo hasta el uso de dos composiciones muy comunes, 
pero paradigmáticas de las dos tradiciones culturales representadas en su obra, esto es, el soneto -tradición occidental- y el haiku -oriental.

En el recorrido por sus libros se dice también que el misterio y la magia de lo cotidiano estarán muy presentes en los primeros textos del poeta, Ocasión donde amarte (1953) o Ahora mismo (1960), proyectándose transversalmente hacia el conjunto de su producción posterior, algo que ya se percibe en la misma elección del léxico y de los campos semánticos. Es preciso señalar aquí el influjo de la memoria, "no el recuerdo", precisa la autora, como cómplice y reveladora de esos objetos, esas "cosas" que nutren la vida diaria, con las que el poeta se identifica al incorporarlas al texto con un singular afán de inventariar la realidad cotidiana y la sencillez de la vida. También de revelarlas en su íntima esencia primordial.

Además el tiempo y el espacio establecerán una lucha dialéctica continua en la obra del manchego. Sobre todo el primero, cuya presencia es más que palpable en el gusto por lo crepuscular como símbolo de retorno a lo esencial. La presencia del tiempo y la preocupación por su huida se perciben abundantemente en los títulos de sus obras. Sin embargo, ambos, tiempo y espacio, deberán ser trascendidos hasta alcanzar el vacío absoluto y necesario. El tiempo "como valor negativo -doloroso, olvido, aniquilador, inclemente- se enfrenta a la nada como valor positivo -con infinita potencialidad y exento de tensiones, olvido balsámico, una nada opuesta al vacío existencial que parecía dictado por el tiempo". Así se incorpora el concepto de la nada y el vacío positivo, conceptos provenientes de las filosofías extremorientales, que suavizan, casi podría decirse que anulan, ese conflicto. La nada, plasmada en la levedad significativa y en la desnudez expresiva, será el fruto de su búsqueda estética y transcendente del valor de la belleza y de la totalidad del mundo. Su hallazgo de lo esencial, y ahí radica su diferencia más importante con los místicos, no está en la divinidad, sino en el concepto del vacío, del mismo modo que para el sufismo, el budismo o el taoísmo. De esta visión de la nada "entendida como espacio sin límites" surgirán otros dos conceptos que irán cobrando mayor protagonismo en la última poesía corredoriana, la ignorancia y la extrañeza.

Dentro de esa confrontación entre el tiempo y la nada, la "mirada" elegida por el escritor vendrá a sintetizar ambos al mostrar diferentes puntos de vista: "la incorporación de la mirada del lector, la conformidad con lo contemplado, la autocontemplación, la reversibilidad de la mirada, el desdoblamiento, la direccionalidad del mirar, la ventana y la terraza como lugares privilegiados desde donde la mirada opera, la mirada en movimiento" ... Todo ello hace que Corredor-Matheos sea el vate cuya obra se acerque, más que la de ninguno de sus contemporáneos, a lo contemplativo, pues "la mirada permite al poeta estar, a la vez, dentro y fuera del objeto observado". Esa mirada desposeída le servirá así como instrumento de conocimiento trascendente y como vía para alcanzar la nada, el vacío absoluto. La mirada resulta un retorno a sí mismo, pero también su máximo baluarte en la búsqueda del conocimiento pleno.

La Naturaleza y la comunión, incluso la fusión, con ella se encuentran al final del camino existencial de preocupación por el destino del hombre, pues a través de ella 
accede también a lo trascendente. Además le servirán para cuestionar la autonomía de la producción intelectual, buscando restituir esa armonía primigenia entre el mundo y el conocimiento. La acción reflexiva y contemplativa, envuelta en el marco natural, "alberga frecuentemente", nos dice la autora, "una semilla de felicidad: el contacto con la naturaleza se contempla como una reconfortante comunión sensorial".

Resulta especialmente significativo el apartado dedicado a los "metapoemas", por su importante presencia dentro de todas las etapas creativas del poeta. Con ellos se va creando un continuum que atraviesa toda su producción y en el que la reflexión sobre el acto creativo o la relevancia del silencio serían el eje central. El yo poético se disuelve en su obra, se funde con ella y con la naturaleza, integrándose en un todo sin límites. De ahí la importancia, ya aludida, de la ignorancia como verdadera sabiduría, pues, nos dice Vega-Sampayo, "saber es ignorar".

Dada la importancia de la reflexión sobre el arte y lo artístico en la trayectoria poética y profesional del manchego, se hace imprescindible el apartado final dedicado a la vinculación entre poesía y fotografía o pintura. Esa confluencia de expresiones extraídas del mundo del arte estará muy presente en algunos poemas muy concretos del grueso de su producción, tanto en los que abundan en referencias paisajísticas de naturaleza pictórica, como en aquellos otros dedicados a la contemplación del poeta de una obra artística, pues "la producción artística -poética, pictórica- le da pie a reflexionar no sólo sobre la misma, sino sobre la propia identidad del yo poético y su integración o separación respecto del objeto".

Este libro, que, por su amplia documentación y sus lúcidas reflexiones, resulta muy útil para acercarse a la poesía de Corredor-Matheos, se cierra, como suele ser común en estos casos, con una bibliografía, tanto de la obra lírica del autor, como de sus traducciones, su prosa, una selección de sus libros en colaboración, ensayos, ediciones; además, claro está, de la bibliografía sobre el poeta y una densa bibliografía general.

Mario Paz González 